\title{
PARASITOLOGY
}

(Founded by G.H.F.Nuttall)

\author{
EDITED BY \\ D. KEILIN
}

IN OONJUNOTION WITH
A. BISHOP
E. HINDLE
F. J. BROWN
C. A. HOARE
P. A. BUXTON
G. LAPAGE
C. DOBELL
K. М. SМITH

P. TATE

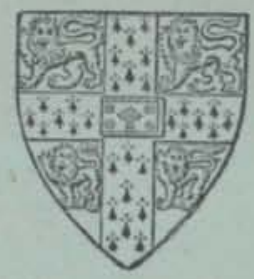

CAMBRIDGE UNIVERSITY PRESS CAMBRIDGE, AND BENTLEY HOUSE, LONDON AGENTS FOR U.S.A.

THE UNIVERSITY OF CHICAGO PRESS

CANADA AND INDIA: MACMILLAN

Thirty-seven Shillings net 
HIGH POWER BINOCULAR MICROSCOPES

for

research and the laboratory

ARE OBTAINABLE

at very keen prices

Second-hand

Guaranteed

By appointment to

H.M. The King

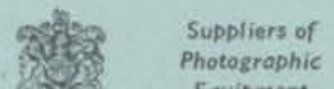

Equipment

\section{WALLACE HEATON} LIMITED

127 NEW BOND STREET, W. 1 Mayfair 7511

MICHROME BRAND-

\section{StAINS \& REAGENTS} FOR MICROSCOPY

Azocarmine B \& G

Azur I \& II

Brilliant Cresyl Blue

Cedarwood Oil

Evans Blue

Fast Green FCF

Giemsa Stain

Indicators

Janus Blue

Janus Green

\section{Janus Red}

Jenner Stain

Leishman Stain

May-Grunwald Stain

Nile Blue Sulphate

Pontamine Sky Blue

Rosolic Acid

Sudan I, II, III \& IV

Sudan Blue

Wax for embedding

Water Soluble Indicators

Stains in tablet form Etc. Etc.

Microscope Slides, Coverslips, Laboratory Sundries

Price Lists on application

EDWARD GURR LTD. 108 WATERFORD ROAD

WALHAM GREEN, LONDON, S.W. 6

Tel.: Renown zorx Cables: Gurr, Renown zorx, London

For UntFors Hich QUaLrTy, ReLtaBultry AND IMMEDIATE DELIVERY, STIPULATE

\section{BRAND}

\section{The}

\section{TREMATODA}

BEN DAWES

A detailed study of the trematode parasites of vertebrate animals such " is the advanced student of zoology dissects in the laboratory,

- ..: of the: Trematoda than can be found in existing works. The author is:Lecturer in Zoology at King's College, London.

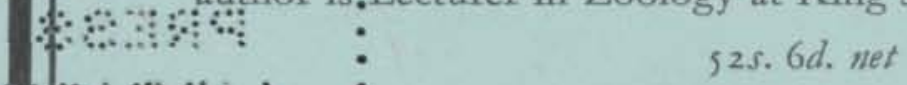

